\title{
DETERMINING THE CRITICAL VELOCITY OF GRASS SODS FOR WAVE OVERTOPPING BY A GRASS PULLING DEVICE
}

\author{
Roel Bijlard ${ }^{1}$, Gosse Jan Steendam², Henk Jan Verhagen ${ }^{3}$ and Jentsje van der Meer ${ }^{4,5}$
}

\begin{abstract}
The strength of the grass sod is an important factor for the stability of a dike in the Netherlands during wave overtopping conditions. Many tests have been performed the last few years with the Wave Overtopping Simulator, leading to the Cumulative Overload Method and a critical velocity. This velocity is a strength parameter of grass on a dike under loads induced by overtopping wave volumes. A new method has been developed to determine this critical velocity, by measuring the force while lifting the grass sod perpendicular to the slope out of the sod. This force is rewritten into the critical grass normal stress which is one of the input parameters for determining the critical velocity of a grass sod. When the critical velocity resulting from this method is compared with the determined critical velocities with the Wave Overtopping Simulator, there is good correspondence between the results for the tested locations. Therefore the sod pulling test could provide results that are reliable enough to determine the critical velocity of a dike section.
\end{abstract}

Keywords: wave overtopping; grass cover; sod pulling device; critical velocity; cumulative overload method

\section{INTRODUCTION}

Since 1 January 2017 there is a shift in the approach for design and safety assessment of coastal structures in the Netherlands. In the past, dikes were designed on the probability of exceedance of a certain event, given by wave conditions during that storm. This has changed to the probability of flooding of the hinterland. In order to determine this flood probability, the strength of the dike has to be known up to breaching of a dike. During extreme storm conditions waves will overtop the crest, which can lead to erosion of the grass sod on the landward slope. This in turn can result in instability of the dike, breaching and flooding of the hinterland. However, if the dike can resist a certain amount of overtopping water without leading to failure of the dike, the crest height does not need to be increased.

In Figure 1 a general cross-section of a dike in the Netherlands is shown. The core of the dike is generally made of sand, but can also be constructed of clay. On top of the core a cover layer of clay is present with some thickness. On the seaward side the clay layer is usually thicker. The top of the cover layer on the crest and landward side is often grass. This is also the case at the upper slope of the seaward side, whereas the lower part has a hard revetment in order to withstand the breaking waves.

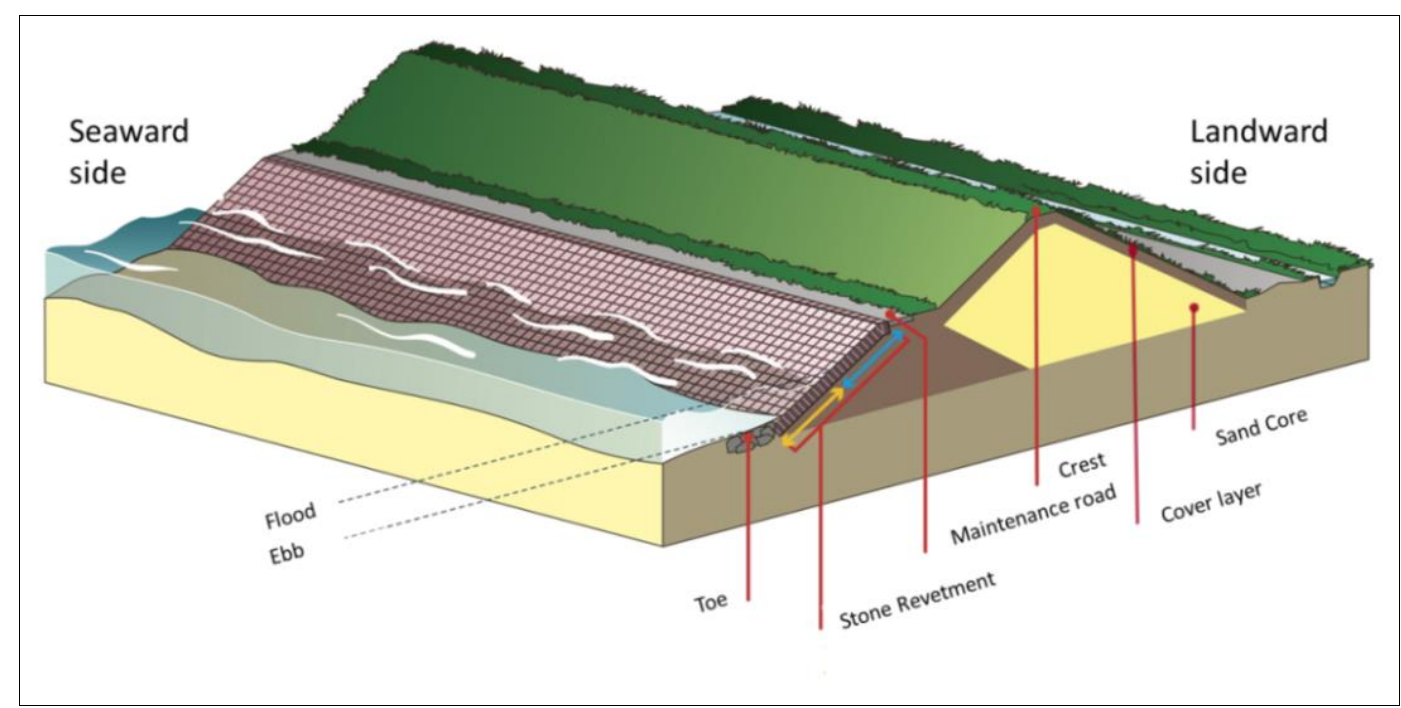

Figure 1. General structure of a dike in the Netherlands

\footnotetext{
${ }^{1}$ ArcelorMittal Projects Europe, P.O. Box 52, Fijnaart, $4793 \mathrm{ZH}$, The Netherlands

${ }^{2}$ Department Flood Defence, Infram International, P.O. Box 150, Maarn, 3950 AD, The Netherlands

${ }^{3}$ Department Hydraulic Engineering, Delft University of Technology, Stevinweg 1, Delft, 2628 CN, The Netherlands

${ }^{4}$ Van der Meer Consulting bv, P.O. Box 11, Akkrum, 8490 AA, The Netherlands

${ }^{5}$ UNESCO IHE, Westvest 7, Delft, 2611 AX, The Netherlands
} 
In order to determine the erosion of the grass sod during wave overtopping, several tests have been performed in the last few years with the wave overtopping simulator (Van der Meer et al. 2008, 2010, Steendam et al. 2012, 2014). When there is a good description of the failure mechanism of a dike during wave overtopping conditions, these tests can show the real strength of the dike. This will avoid unnecessary improvements of dikes for lack of knowledge, which otherwise leads to excess safety of the dike and too early investments. A critical velocity can be determined with the wave overtopping simulator per location, as a parameter for the strength of that dike section. The critical velocity is one of the input parameters in the Cumulative Overload Method, which is used to determine the strength of a dike under overtopping wave volumes (Steendam et al. 2014).

There is a difference in wave climate between river and sea dikes. A river dike will have a lot of small overtopping waves during a storm event, whereas at a sea dike only a few large waves will overtop the crest. Until recently the mean wave overtopping discharge was the governing parameter for dike safety. A problem with this criterion is that waves with a large volume and velocity do not have a bigger impact on the erosion of the grass layer than the smaller waves. In reality however, larger overtopping waves contribute most to the erosional process and smaller waves have less impact on the erosion. Therefore the front velocity of the overtopping wave is used to describe overtopping waves on dikes in the Cumulative Overload Method.

\section{Sod Pulling Method}

To allow a certain wave overtopping, the strength of the dike and in particular the strength of the grass sod has to be known. For the testing of the strength of the grass a simple testing method is preferred, since dike managers may use it in the future to assess the strength of their dike sections. The Wave Overtopping Simulator tests are complex and time consuming, which makes it not really suitable for a dike manager to use for many dike sections. Therefore a new method of testing the strength of the grass sod has been developed.

This new method, called the sod pulling method, tests the actual strength of the grass by lifting the grass sod out of the top layer (Steendam et al. 2014). During the sod pulling test the vertical force required to lift a grass sod out of the top layer is measured. Four pins are anchored horizontally into the sod at 4 centimeters below the surface, to prevent the pins from tearing through the sod. In order to insert the pins into the sod, the soil has to be removed from at least two sides of the frame (see Figure 2a). Because of this, it is not possible to test the strength of an intact grass sod with this device. The sod is lifted by a hydraulic cylinder which is manually operated with a steering wheel (see Figure 2b). This cylinder induces an increasing displacement on the grass sod, until the sod fails and is pulled out of the top layer (Figure 2c). During the tests the force and displacement have been measured (and recorded) four times a second. This data is then used for the analyses of the strength of the sod. There are many variations possible with this sod pulling device, like saturation of the sod, different frame sizes and so on. There are also two test conditions of the grass sod:

1. Condition 2: The frame will be placed on top of a sod, where 2 sides are cut before testing. The other 2 sides and the bottom of the sod will provide resistance against the uplifting force.

2. Condition 4: The frame will be placed on top of a sod where all the sides are cut (Figure 2c). In this way, only the bottom of the sod will resist against the imposed displacement of the hydraulic cylinder.
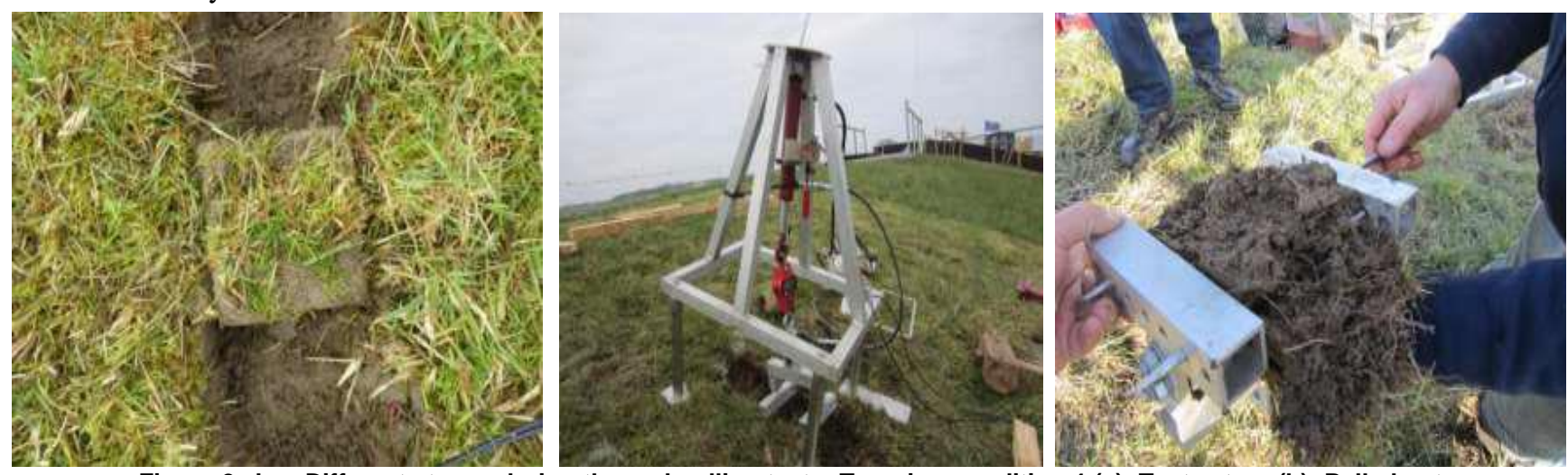

Figure 2a,b,c. Different stages during the sod pulling tests: Top view condition 4 (a); Test set-up (b); Pulled out $\operatorname{sod}(c)$ 


\section{Influences on the strength of the grass sod}

The grass cover consists of small and large particles, pores and roots. The smaller clay particles can group together, which creates aggregates of several centimeters. A network of roots is often densely packed and the roots act as anchor to keep soil particles together. The aggregates are kept together by very fine root hairs and symbiotic fungal threads in the soil. Large particles are held together by the coarser roots in the top layer. This network of fine and coarse roots may lead to a strong, flexible and permeable grass sod. Without the anchoring effect of the roots, i.e. bare clay, individual particles are easily washed away during storm conditions. When hydraulic loads are acting on the sod, the weakest roots will break first, but the force will be redistributed to other roots. This will weaken the sod slightly until the displacement of the sod reaches critical values. Then the redistribution is not possible anymore and the sod will fail.

The grass sod is subjected to various influences which determine the strength of this layer. These influences can be divided into two groups, natural and man-made. Examples of natural influences are the caves and tunnels dug by mice and moles. Man-made examples are wheel tracks due to mowing and hay-making, fences and stairs on the slope for visitors, etc. These factors damage the grass sod and result in local weak spots on the slope which have less resistance against wave overtopping.

The structure and strength of a grass cover is also influenced by the different seasons of a year. When looking at the root density, there is a factor 0.5 difference in the number of roots between the different seasons (Alterra, 2014). The more roots present in the grass sod, the stronger the interlocking is between the roots and the soil particles. This in turn leads to a stronger grass sod in the summer months compared to the winter months. The regenerative ability of the sod is also higher in the summer; small damages in the sod are more quickly repaired to its original state. This difference in sod quality is large, therefore the governing conditions of a dike depend on the period when the maximum loads are expected. For sea dikes, the storm conditions in the winter months will be decisive in the Netherlands, whereas the highest loads on river dikes can occur year round.

Another influence on the erodibility of the top layer is the saturation of the soil. Above the ground water table the pores in the clay cover are usually not fully saturated. As a result, the pore pressure is negative compared to the atmospheric pressure. This negative pore water pressure is called the suction pressure, as in this situation the clay can "suck up" water from the water table. The suction pressure keeps a thin layer of water around the aggregates. As more water is drained the layer grows thinner, leading to an increased suction pressure. When the ground is completely saturated the suction pressure is zero. The suction pressure has to be overcome first, before the grass sod can be lifted upwards. The higher the suction pressure, the higher the resistance is against the erosion of the sod. Pore water pressure can only become positive in the larger pores, when water percolates through these open spaces due to infiltration of outside water. The smaller pores inside the aggregates will still experience suction pressures, since water does not infiltrate quickly into the aggregates itself. As a result of the water overpressures, the water in the larger pores is attracted towards the pores in the aggregates. This leads to a slowly expanding aggregate. This process is shown in Figure 3 (Hoffmans, 2012).

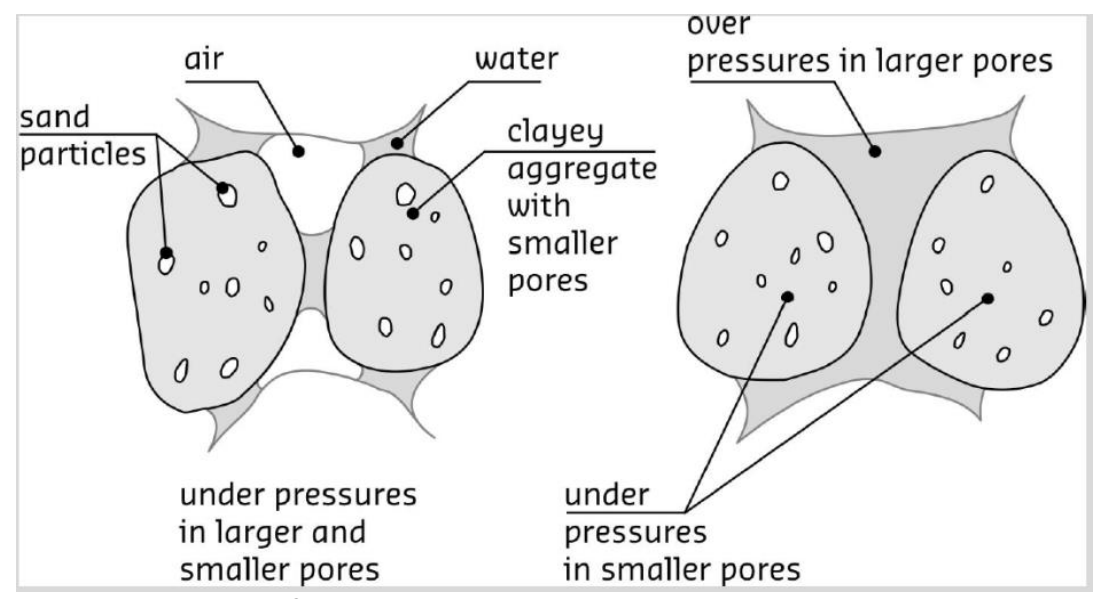

Figure 3. Clayey aggregates experiencing suction pressures 


\section{SOD PULLING TEST RESULTS}

During the research five different locations in the Netherlands were tested with the sod pulling method. The first location was on a river dike (near Millingen aan de Rijn), the other four locations on a sea dike (Boonweg 1-4, Sint Jacobiparochie). All five locations have been tested with the Wave Overtopping Simulator in the past, which makes it possible to compare the results of the sod pulling tests with the results from the Wave Overtopping Simulations. Various tests have been performed in order to investigate different influences on the strength of the grass sod. All tests are performed under fully saturated conditions, by artificially watering the grass sod. This means that the suction pressures in the sod are reduced to zero.

The following topics will be discussed below with respect to strength of a grass cover:

1. Influence of the frame size used

2. Strength of an intact grass sod

3. Strength at the various locations

4. Influence of the daily maintenance on the strength of the grass cover

5. Influence of the saturation of the grass sod

6. Strength of the bare clay underneath the grass

\section{Influence of the frame size used}

Different frame sizes have been used during the tests. The 10 by 10 centimeter frame size leads to inaccurate results, since the local deviations (due to the heterogeneity of the sod) have too much influence on the outcome. Therefore, the results from this frame size are not used in the analyses for the strength of the grass sod. The $15 \times 15$ centimeter and 20x20 centimeter frame size have a larger area of testing, which reduces the influence of local deviations. The coefficient of variation of these two frame sizes is in order of $15 \%$ leading to more reliable results. However, during the cutting of the sides, the sod is disturbed on local scale. For larger frame sizes these disturbances have less influence on the end result because of the larger area of the sod. Frame sizes larger than 20 by 20 centimeters cannot be lifted with the current sod pulling device, therefore testing with this frame size is preferred in further research.

\section{Strength of an intact grass sod}

With the sod pulling method the grass sod is pulled up with 2 or 4 sides cut before testing. However, during wave overtopping the grass sod is still fully intact, all sides are still connected so that there is an undisturbed grass layer. In order to determine the strength during wave overtopping, the strength of an intact grass sod needs to be determined. Furthermore, it is convenient to express the strength of the intact grass sod in a critical normal stress $\left(\sigma_{\text {grass,c }}\right)$, because this is independent of the frame size. The loads during wave overtopping are also often expressed in terms of stresses, so it enables a good comparison with the strength.

There are two methods available for calculating the strength needed to pull out an intact sod. They are based on different principles, one practical and one more theoretical.

1. The theoretical approach by Hoffmans (2012) is based on the exponential decrease of the root density over the depth. Since the roots provide most of the strength in the sod, the decrease of the number of roots will lead to a decrease in strength.

2. A practical approach is based on the relation between test condition 2 and 4 . When 2 sides are cut during the testing, the other 2 sides and the bottom of the sod provide the support against the pulling force induced by the hydraulic cylinder. With condition 4, only the bottom provides this resistance. When both methods are combined the strength of an intact sod can be calculated. An additional problem of the cutting of the sides before testing is that the cuts influence the strength and the shape of the sod, especially at the corners of the pulled sod (see Figure 4). The red circles indicate the corner areas which are reduced in thickness and also in strength. When the basic principle is that the area of the sod has a linear relation with the resistance against uplift, the missing area in the corners has to be taken into account. When the frame sizes increases the total tested area increases and the influence of the cutting of the corners decreases. When the area of the corners is related to the total area of the sod, a shape factor can be determined. This shape factor $\alpha$ has a value of 1.10 for the $20 \times 20 \mathrm{~cm}$ frame size and 1.15 for the $15 \times 15$ centimeter frame size. 

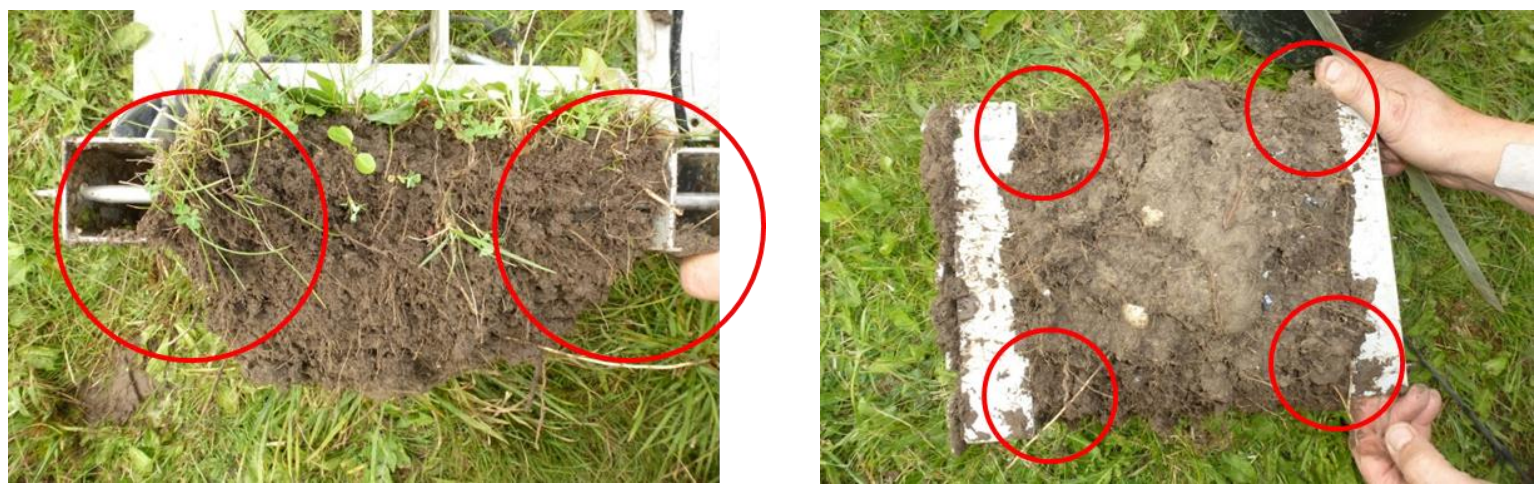

Figure 4. Photos of side and bottom view of missing corners due to the cutting

For the practical method a relation between conditions 2 and 4 has to be established. It is possible to match the measured force from condition 2 with a measured force from a condition 4 test. This matching can be done by arranging them on measured strength, where the largest condition 2 force $\left(F_{2}\right)$ is matched with the largest condition 4 force $\left(F_{4}\right)$. A large $F_{2}$ means that it was a locally stronger part of the grass layer and the same holds for a large $F_{4}$. Therefore it is possible to compare both test results with each other. The strength of an intact sod is divided by the total area of the sod (bottom area $A_{b}$ and the area of the 4 sides $A_{s}$ ), in order to find the critical grass normal stress. The equations used are:

$$
\begin{gathered}
\sigma_{\text {grass }, c}=\frac{F_{i}}{A_{b}+4 * A_{s}} \\
F_{i}=\alpha *\left[F_{2}+\left(F_{2}-F_{4}\right)\right]
\end{gathered}
$$

In Figure 5 the results from all the tests are grouped per approach and summarized per location in one small square. The large circles are the averages of all locations per test method. The left point per testing method is from the theoretical method, the right point in the same color is the practical method.

The theoretical method leads to inconclusive results, because the values for the critical grass normal stresses are not in the same order for condition 2 and 4 . Condition 4 gives significantly higher stresses compared to condition 2. Both testing methods should give approximately the same results, since the tests are all performed on the same grass layer.

The practical approach gives more constant, but significant lower values for the critical grass normal stress than the theoretical approach. This can be explained by the fact that the theoretical approach is based on an ideal situation, where coverage and amount of herbs do not influence the root density. Furthermore, saturation and maintenance have no effect on the outcome in the theoretical approach. It is assumed that the practical approach gives more accurate results and is therefore used for further analyses.

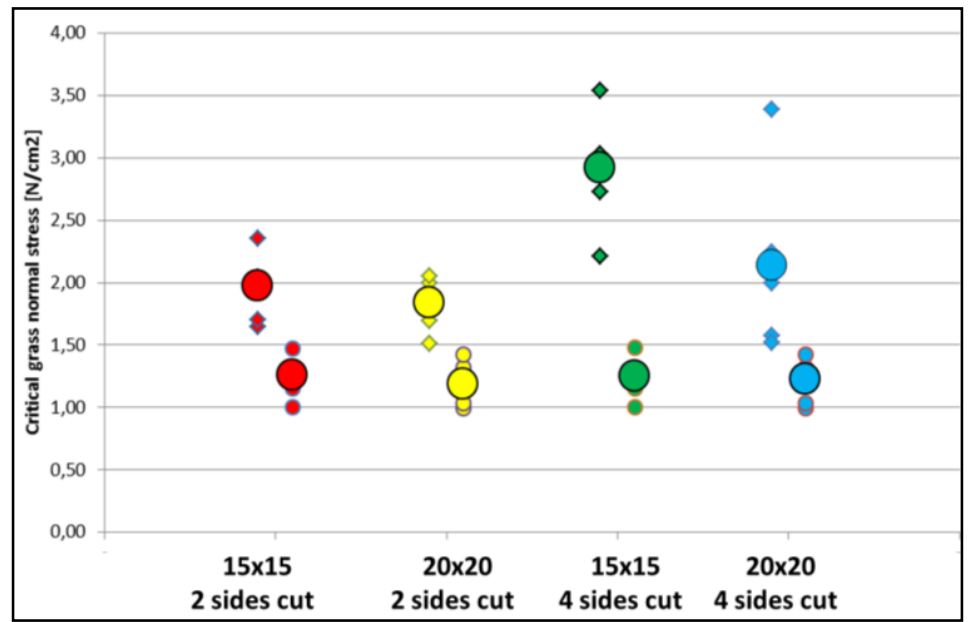

Figure 5. Comparison of the theoretical (left point) and practical method (right point) for calculating critical grass normal stress of an intact sod 
A disadvantage of the practical method is that twice the numbers of tests have to be performed in order to combine two results (conditions 2 and 4) and to calculate the strength of an intact grass sod. However, it is possible to calculate the strength of the intact sod directly from condition 2 with an empirical factor, see Figure 6. This factor is calculated from the force required to extract an intact grass sod divided by the corresponding force of the condition 2 test. The amplification factor should have values higher than one, but for one test in Millingen this is not the case. This would mean that the strength of an intact sod is smaller than the tested sod with 2 sides cut loose. The result for that condition 2 test was so small that there was no corresponding value with the condition 4 test found during testing. This should not be possible, but is a result of the coupling of the data. Since the averages are the key values here, this point is neglected.

The amplification factor is on average almost constant around 1.56, independent of the location and frame size used. When the force measured during condition 2 is multiplied by an amplification factor of 1.56, it will result in the force needed to extract an intact sod. This force still needs to be divided by the area to find the critical grass normal stress. In this way, the total number of tests required is halved by excluding the condition 4 tests from the test set-up.

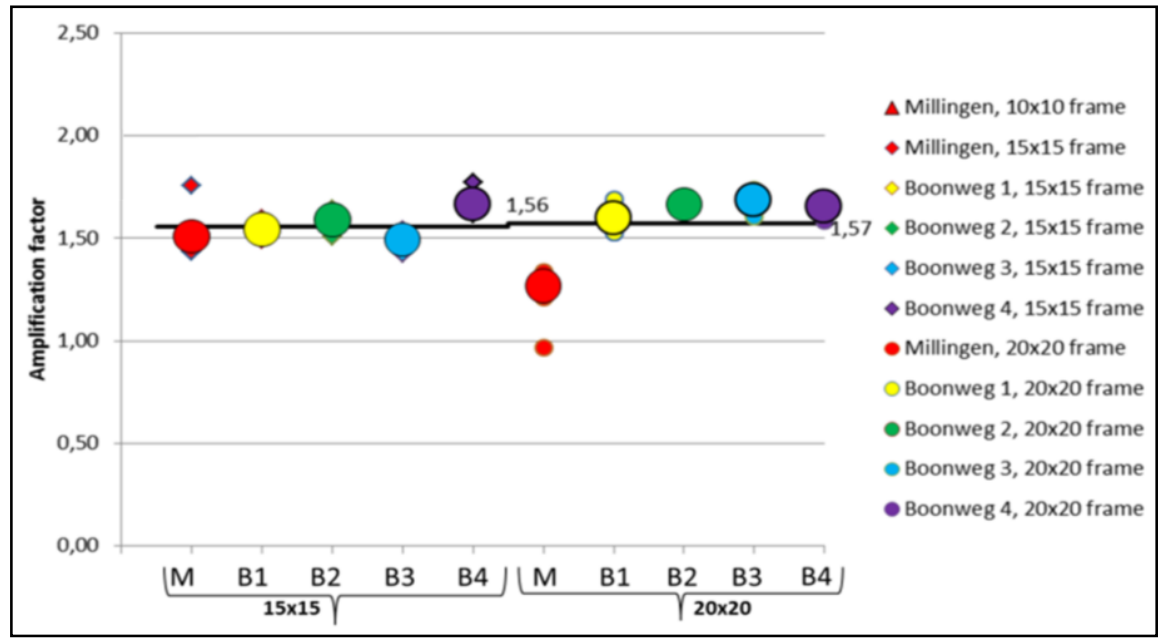

Figure 6. Amplification factor to calculate the required force to extract an intact sod from a condition 2 test

\section{Strength at the different locations}

Due to heterogeneity of a grass cover the results of the same type of test can show large scatter, even when the tests are performed in close proximity of each other. Figure 7 shows all the regular tests done at the various locations. The smaller shapes represent the individual tests, where the thick line is the average per location. Different locations are characterized by their own color in the graphs.

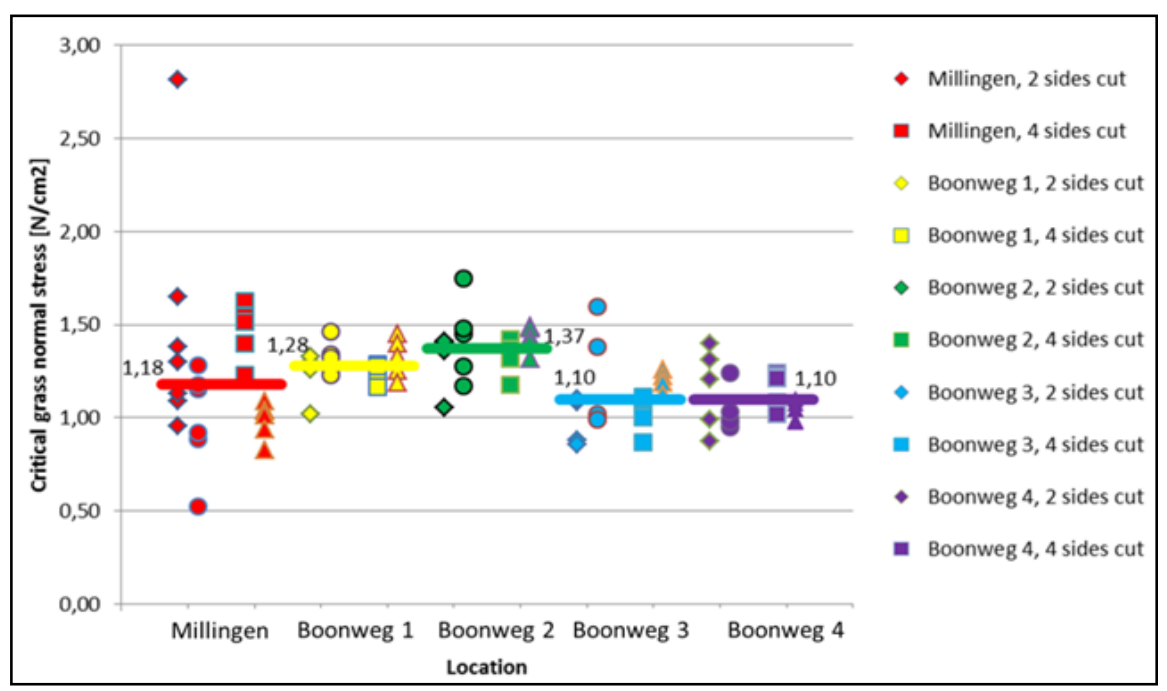

Figure 7. Critical grass normal stress for the $15 \times 15$ (left point) and $20 \times 20$ frame size (right point) at 5 different locations resulting from the sod pulling tests 
In older assessment methods in the Netherlands to determine the strength of the grass it is mentioned that the coverage and the amount of herbs may have influence on the strength. A problem however is that even when the areas look visually the same, there can be a relative large difference in the maximum measured force. This discrepancy cannot be excluded from the tests, it is characteristic for a grass sod. Because of this, the individual test results are not the most important data. All the data on the same location have been combined into an average value $(\mu)$, with a standard deviation $(\sigma)$ and a corresponding coefficient of variation $(C v)$, see Table 1 .

\begin{tabular}{|c|c|c|c|}
\hline Location & $\mu$ & $\sigma$ & $\mathrm{Cv}$ \\
\hline Millingen & 1.18 & 0.27 & $34 \%$ \\
\hline Boonweg 1 & 1.28 & 0.10 & $8 \%$ \\
\hline Boonweg 2 & 1.37 & 0.14 & $10 \%$ \\
\hline Boonweg 3 & 1.10 & 0.17 & $16 \%$ \\
\hline Boonweg 4 & 1.10 & 0.14 & $12 \%$ \\
\hline
\end{tabular}

Influence of the maintenance on the strength of the grass layer

During the present investigation four different grass types were tested, which only differ in the daily maintenance that has been applied for more than 20 years. The different maintenance types are listed below per location.

- Millingen: No grazing, twice hay-making, no fertilization

- Boonweg 1: Periodic grazing with low sheep intensity, with $70 \mathrm{~kg} \mathrm{~N} / \mathrm{ha}$ fertilization

- Boonweg 2: Twice intensive grazing, one time hay-making, no fertilization

- Boonweg 3: No grazing, twice hay-making, no fertilization

- Boonweg 4: First haymaking, then grazing, followed by an extra hay-making, no fertilization.

The expected strength on the basis of the former theory based on the different maintenance types (Rijkswaterstaat, 2012) is that Boonweg 1,2 and 4 are expected to have a moderate grass strength and Boonweg 3 and Millingen a higher strength. However, this is not the case (see Table 1), since the sod pulling test show that Boonweg 1 and 2 have a stronger grass sod compared to the other sections, just opposite to the former approach.

The most important difference between the sod pulling tests and the maintenance method is the influence of grazing on the strength of the grass sod. Boonweg 3 and Millingen do not allow grazing on the dike which results in a lower average strength. This may be explained by the grass cover that becomes more open (more porosity) if sheep do not make the top of the grass more dense by their weight. Boonweg 1,2 and 4 do allow grazing on the slopes, but only Boonweg 4 results in a lower strength (Figure 7). At this section twice a year hay-making is performed, which can possibly have negative influence on the strength. The difference between Boonweg 1 and 2 is the use of fertilization. This difference would suggest that usage of fertilizers has negative influence on the strength of the sod. This is in accordance with the accepted theory.

\section{Influence of the saturation of the grass sod}

During storm conditions the cover layer of the sea dike will be completely saturated. There are no suction pressures left in saturated soil, leading to less resistance against uplifting of the sod. In order to simulate these conditions during the sod pulling tests the soil has to be watered artificially before testing. However, the wave overtopping conditions at river dikes can occur with unsaturated soil conditions, due to high river discharges in summer time. So it is interesting to see how much these suction pressures contribute to the strength.

The influence of the saturation of the top layer is tested by doing tests under unsaturated conditions (no artificial watering at all). These tests resulted in higher values for the measured forces compared to the tests under fully saturated conditions. Depending on the degree of saturation (influenced by the daily weather during testing) the suction pressures result in a measured force with a factor up to 1.4 higher for unsaturated soil. However, there is not yet enough data for determining this factor exactly, so future sod pulling tests should be performed under fully saturated conditions. These conditions are also more common during storm events, since the saturation of the top layer will increase with each overtopping wave. An unsaturated top layer is stronger, so also for safety reasons it is better to test the grass sod under fully saturated conditions. 


\section{Strength of the clay underneath the grass sod}

The top layer of a sea dike in the Netherlands generally consists of a grass sod built on a clay layer of with certain thickness. During wave overtopping small spots of grass can erode, but the underlying clay layer still provides some resistance against the overtopping waves. This clay layer protects the core of the dike. When the clay is eroded, the dike core will be exposed and this will quickly lead to complete failure of the dike section. In the top twenty centimeter of the clay layer are grass roots present, which decrease in number and strength from top to bottom. These roots provide extra resistance against the erosion compared to bare clay. With the sod pulling tests the remaining strength of the top clay layer is tested after the grass itself is eroded away. The top layer is tested at 6 $\mathrm{cm}$ depth and at $10 \mathrm{~cm}$ depth. The force needed to extract a clay sod at $6 \mathrm{~cm}$ depth is about $70 \%$ of the strength needed for a normal grass sod. The strength of the clay sod at $10 \mathrm{~cm}$ depth is about $45 \%$ of the original strength. It was established in previous research that the strength of pure clay of decent quality was only $0.075 \mathrm{~N} / \mathrm{cm}^{2}$ (Hoffmans, 2012). The values found with the sod pulling test are significantly higher, since they are in the order of $0.5-0.9 \mathrm{~N} / \mathrm{cm}^{2}$. Therefore the few roots and the resulting structured clay have a big impact on the strength of the clay layer.

\section{CUMULATIVE OVERLOAD METHOD}

Wave overtopping is generally described by an average wave overtopping discharge. However, this discharge does not make a distinction between mild and severe wave conditions. Severe (sea) wave conditions have in general only a few waves overtopping the crest, but these waves have a large volume. The milder (river) wave conditions result in a lot of waves with a small volume overtopping the crest. However, both wave conditions can give the same average wave overtopping discharge, see also chapter 3 in EurOtop (2016). Since there is a distinct difference in the loads caused by these two wave overtopping climates, it is important to find a parameter that can describe this difference in behavior. This is possible with the Cumulative Overload Method.

It is important to determine the effect of overtopping waves on a slope. When overtopping wave volumes run over the crest onto the landward side of the dike, damage will start to develop over time. There are different stages of damage, of which failure of the dike is the easiest to define. When the top layer of the dike (grass cover with clay layer) is eroded, the core of sand will become visible. This core has almost no resistance against the overtopping wave volumes, which leads to rapid erosion of the core. This will quickly lead to complete failure of the dike section. Therefore it is assumed that when the sand core is reached, the dike section has failed. It is possible to define more stages of damage during wave overtopping, such as first damage to the grass sod. A disadvantage of this criterion is that a small hole can already exist in the top layer, even before testing begins. Also a very weak spot in the grass layer can quickly result in a small hole. Because of this it is preferred to use various damaged locations as a criteria. This takes into account that one small weak spot is less important for the entire dike section.

From the extensive testing with the Wave Overtopping Simulator it is known that failure is the most important damage factor to establish the critical velocity of a grass slope. The least reliable damage indication is initial damage. Sometimes initial damage occurs quite soon, whilst the slope appears to be very strong, sometimes initial damage occurs just before the slope fails.

Another possibility is that the dike section did not fail during the overtopping simulation tests. This can also be used as a damage criterion. In short, the following criteria will be used, of which examples are shown in the Figures 8a to 8d (Van der Meer et al., 2010).

- First damage (Figure 8a)

- Various damaged locations (Figure $8 b$ )

- Failure (Figure 8c)

- Non-failure after testing (Figure 8d) 

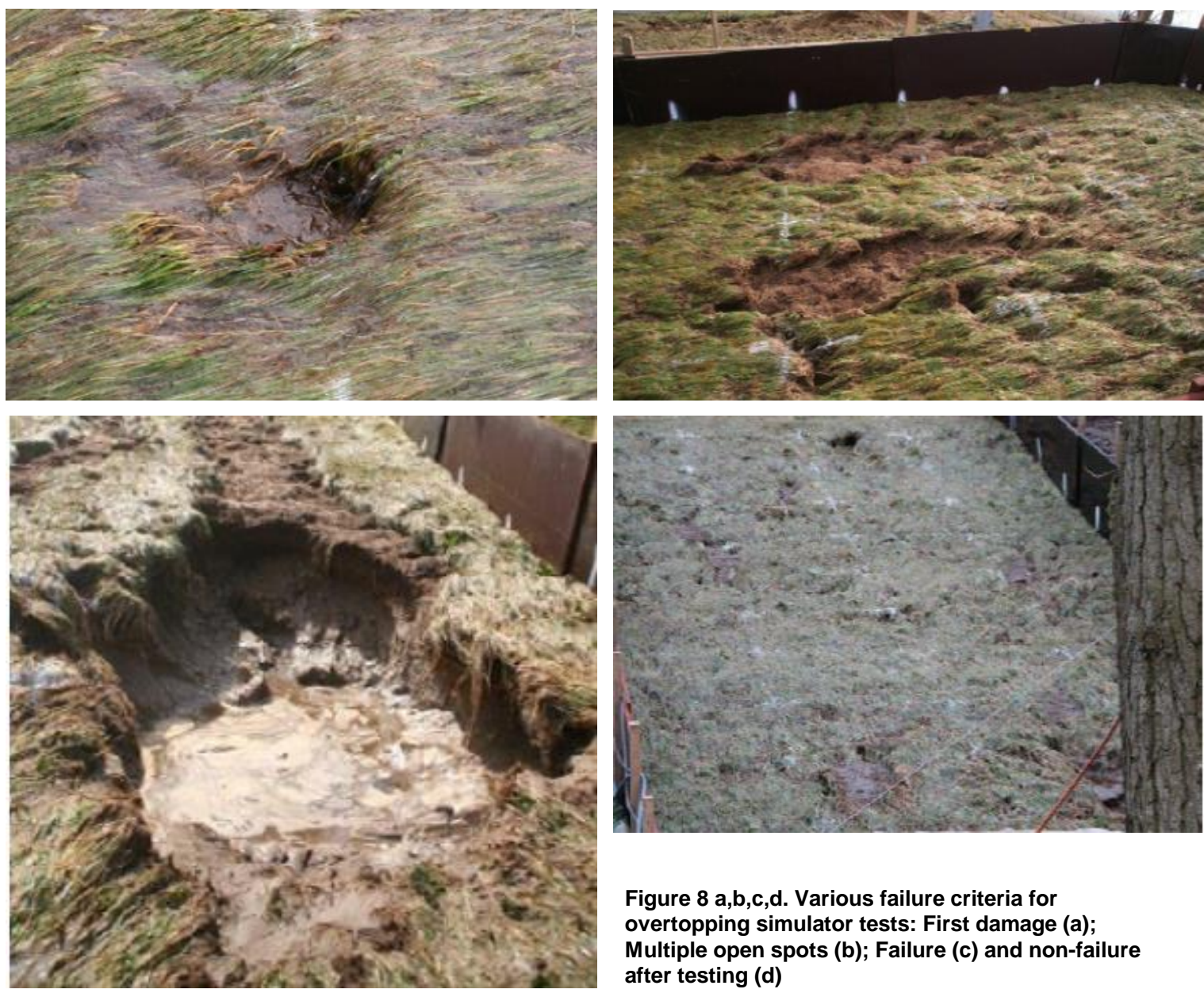

Figure 8 a,b,c,d. Various failure criteria for overtopping simulator tests: First damage (a); Multiple open spots (b); Failure (c) and non-failure after testing (d)

There are different ways to determine the erosional development. Dean et al. (2010) worked on erosional equivalence with a time dependent factor in the formulations. The erosion could be described with an excess velocity $(u)$, an excess of shear stress $\left(u^{2}\right)$ or as an excess of work $\left(u^{3}\right)$. The front velocity of the overtopping waves is an important parameter, which can be compared with a critical velocity $(U c)$. However, this research was carried out for continuous overflowing water over the dike, which is not completely comparable with wave overtopping. The time factor of overtopping waves is not that important, since it is a short interval (1-3 seconds) and the velocities are higher. The higher velocities decrease the time influence even further, so the duration can be excluded from the equation for erosion during wave overtopping. The theory of shear stress with a threshold is taken as a basis for development of erosion (Hoffmans et al. 2008). This theory was confirmed during the wave overtopping simulation tests at the Vechtdijk, where smaller wave volumes did not contribute to the development of damage. This threshold is given as a critical velocity $(U c)$ which must be exceeded before damage can start to occur (Van der Meer et al., 2015, Steendam et al. 2016). This leads to Equation 3 called the "Cumulative Overload Method"

$$
D=\sum_{i=1}^{N}\left(\alpha_{M} U^{2}-\alpha_{S} U c^{2}\right) \quad \text { for } \quad \alpha_{M} U^{2}>\alpha_{S} U c^{2}
$$

The damage factors $D\left(\right.$ in $\left.\mathrm{m}^{2} / \mathrm{s}^{2}\right)$ in the Cumulative Overload Method have been determined during the wave overtopping simulation tests at the Vechtdijk near Zwolle (The Netherlands) after recalibration.
- Start of damage
- Various open spots
$\mathrm{D}=1000 \mathrm{~m}^{2} / \mathrm{s}^{2}$
- Failure
$\mathrm{D}=1000 \mathrm{~m}^{2} / \mathrm{s}^{2}$
$\mathrm{D}=4000 \mathrm{~m}^{2} / \mathrm{s}^{2}$
$\mathrm{D}=7000 \mathrm{~m}^{2} / \mathrm{s}^{2}$ 
In Equation $3 \alpha_{M} U^{2}$ represents the load factor of the overtopping wave on the grass sod, in which $\alpha_{M}$ is an amplification factor for the actual velocity of the overtopping wave $(U)$ due to objects or transitions on the slope (SBW, 2012). The amplification factor is larger or equal to 1, so more waves will contribute to the damage around obstacles and transitions.

The term $\alpha_{S} U c^{2}$ represents the strength factor of the grass sod. Objects and transitions on slopes can also reduce the strength of the grass near that object or transition. Therefore on the strength side a factor $\alpha_{S}(\leq 1)$ is used. This can be for instance because of the additional difficulty of mowing near these places or the placement of stones underneath the sod at the toe leading to a weaker grass sod. Also the direction in which the grass is hindered to grow due to the obstacle is important. When there is a vertical transition at one side of the grass, the roots cannot penetrate the soil in that direction. This leads to loss of strength that can resist the uplifting force.

\section{Critical velocity if no sign of damage after testing}

Two of the tested locations at the Boonweg (Boonweg 1 and 2) did not show any damage during the wave overtopping simulator tests. Therefore none of the existing damage factors is met and it is not possible to give a good approximation of the critical velocity for these grass sods. This in turn leads to difficulties when comparing it with the results from the sod pulling tests. In order find the link between the sod pulling tests and the wave overtopping simulations, a new factor is introduced for no visible damage after testing with the overtopping simulator.

When there is no sign of damage on the slope after the complete overtopping simulation the damage factor is at least lower than that of failure $\left(=7000 \mathrm{~m}^{2} / \mathrm{s}^{2}\right)$. However, it is difficult to say how much lower since the section did not fail and there is no knowledge of how close to failure the slope was at the end of the test. For example, at Boonweg 3 and 4 the start of damage criterion was immediately followed by failure of the dike. At these sections the bulging mechanism (Infram, 2008) was the first visible damage, but led to failure at the same time. On the other hand, start of damage has not occurred, so it could also be assumed that the damage factor is lower than $1000 \mathrm{~m}^{2} / \mathrm{s}^{2}$. How much lower the criterion should be cannot be determined without additional data. Therefore the value of $1000 \mathrm{~m}^{2} / \mathrm{s}^{2}$ is also used as an approximation. So when no damage is visible after the wave overtopping simulator tests (Boonweg 1 and 2), the estimation of the damage factor is between 1000 and $7000 \mathrm{~m}^{2} / \mathrm{s}^{2}$. It is not possible to give a more precise, since the first two damage criteria (start of damage and various open spots) are not always visible. To conclude, the following four damage factors are used:

- No sign of damage $1000 \leq \mathrm{D} \leq 7000 \mathrm{~m}^{2} / \mathrm{s}^{2}$

- Start of damage $\mathrm{D}=1000 \mathrm{~m}^{2} / \mathrm{s}^{2}$

- Various open spots $\mathrm{D}=4000 \mathrm{~m}^{2} / \mathrm{s}^{2}$

- Failure $\quad \mathrm{D}=7000 \mathrm{~m}^{2} / \mathrm{s}^{2}$

The new criterion for 'No sign of damage' is used to determine the critical velocity of the two tested sections at the Boonweg 1 and 2 which did not fail with the wave overtopping simulator. This leads to a range of values which the critical velocity could be based on the simulations. For the other sections the critical velocity was estimated by Van der Meer in 2015. Later it appeared that there was a small error in the determination of the critical velocity for Millingen, which resulted in a too low value $(6 \mathrm{~m} / \mathrm{s})$. This has been rectified so that the grass sod in Millingen has the correct critical velocity of $7 \mathrm{~m} / \mathrm{s}$. Table 2 gives an overview of the critical velocities for the five tested sections determined with the wave overtopping simulator.

\begin{tabular}{|l|c|}
\hline $\begin{array}{l}\text { Table 2. Critical velocity of various locations } \\
\text { based on wave overtopping simulator tests }\end{array}$ \\
\hline Location & Uc [m/s] \\
\hline Millingen & 7 \\
Boonweg 1 & $8-9.5$ \\
Boonweg 2 & $8-9.5$ \\
Boonweg 3 & 8 \\
Boonweg 4 & 8 \\
\hline
\end{tabular}




\section{DETERMENING THE CRITICAL VELOCITY FROM SOD PULLING TESTS}

The objective is to find the relation between the critical velocity in the Cumulative Overload Method and the results from the sod pulling tests. In order to find this relation, more insight is required into the critical velocity. Hoffmans $(2008,2012)$ developed a formula for the critical velocity, which will be used as the basis for this relation.

$$
U_{C}=\alpha_{\text {grass }, U} * r_{0}^{-1} * \sqrt{\frac{\psi_{c}\left(\sigma_{\text {grass }, c}-p_{w}\right)}{\rho}}
$$

In the above equation $r_{0}$ is the relative turbulence of the overtopping wave over the slope. This is a relatively unknown parameter, since turbulence is difficult to measure. $\Psi_{c}$ is the Shields parameter for transport of soil under flow velocities. $\sigma_{\text {grass,c }}$ is the critical normal stress of the grass sod determined with the sod pulling tests. The pore water pressure (or suction pressure) is given as $\mathrm{p}_{\mathrm{w}}$, which increases the strength of the unsaturated soil. The suction pressures should be overcome before the grass sod can be lifted up. The density of the water is given by $\rho$ and $\alpha_{\text {grass } U}$ is a constant with the value of 2.0. The above parameters influencing the critical velocity will be discussed separately in the below sections.

\section{Shields parameter}

The Shields parameter is based on the transport of loosely packed sand on a river bed assuming that the movement of particles is caused by a shear stress (or bed shear velocity) on the particle. This parameter has a value between 0.03 and 0.06 for larger particles in turbulent flow, but this cannot be directly compared with the erosion (or movement) of the grass sod during wave overtopping conditions. Therefore the Shields parameter is assumed to be a constant for grass erosion in general, with a value of 0.03, which is also used by Hoffmans (2012). Since it is used as a constant, it can be removed as an input parameter from Equation 4 and added to the existing constant $\alpha_{\text {grass }, \mathrm{U}}=2.0$ leading to $\alpha_{\text {grass }, \mathrm{c}}=0.34$ and Equation 5 .

$$
U_{C}=\alpha_{\text {grass }, c} * r_{0}^{-1} * \sqrt{\frac{\left(\sigma_{\text {grass }, c}-p_{w}\right)}{\rho}}
$$

\section{Pore water pressure}

The pore water pressure $\left(p_{w}\right)$ represents the suction pressure in the roots and has a negative sign (for example $-10 \mathrm{kN} / \mathrm{m}^{2}$ ), resulting in an increase in the critical velocity of the slope. At the moment the top layer is fully saturated, the pore water pressure is equal to zero. This is most likely during storm conditions, which is often accompanied by heavy rain leading to a fully saturate sod. But in summer time it is possible that there are high river discharges leading to overtopping waves. This can be caused by storm conditions further inland. During these conditions, the top layer of the dike is not fully saturated, resulting in suction pressures in the sod. However, with each overtopping wave the sod will become more and more saturated. The suction pressure needs to be included in the equation for the critical velocity as long as the soil is not fully saturated, but its (positive) effect on the strength will decrease with each overtopping wave. Before the sod pulling tests started the ground was artificially watered, leading to no suction pressures in the soil. Also during the wave overtopping simulations no suction pressures were present in the sod, so this factor is set at zero in this research.

\section{Relative turbulence intensity}

The relative turbulence intensity is a relatively unknown parameter and is linearly related to the critical velocity (see Equation 5) in the formula by Hoffmans. However, turbulence is a load factor, caused by the overtopping wave volumes. At this moment it is in the formula for the critical velocity, which is a strength factor. This is not fully correct and should be looked at in later research. During this study Equation 4 from Hoffmans is used, neglecting the above observation.

This factor is estimated between 0.10 and 0.20 for overtopping waves on a slope. The further down the slope, the higher the velocity on that location and the lower the relative turbulence. During the wave overtopping simulations most of the damage occurred at the bottom half of the slope, so a low relative turbulence intensity should be used as estimation. The factor has been fitted on 0.12 for the damage found on the tested locations, since the front velocity of the overtopping wave could increase further downward of the slope near the toe (so less turbulence). When damage is found higher up on the slope, the relative turbulence intensity could be increased up to a maximum of 0.20 
for damage at the crest of the dike. The value of 0.12 for the relative turbulence intensity is also used for the Boonweg 1 and 2 where was no sign of damage was visible over the slope. At other tested locations most of the damage started at the downward side of the slope, so this is also expected for the Boonweg sections 1 and 2.

The relative turbulence can be related to the roughness of the slope, using Equation 6. In this equation is $\mathrm{C}$ the Chézy coefficient, $\alpha_{0}$ a coefficient with a value of 1.2 and $\mathrm{g}$ the gravitational acceleration. When the value of 0.12 is taken for the relative turbulence, the Chézy coefficient is approximately $30 \mathrm{~m}^{1 / 2} / \mathrm{s}$. This is inside the range for the roughness of a grass sod with values between 25 and $80 \mathrm{~m}^{1 / 2} / \mathrm{s}$ (Hoffmans, 2012).

$$
r_{0}=\frac{\alpha_{0} * \sqrt{g}}{C}
$$

\section{Critical grass normal stress}

For all the sections tested with the sod pulling device, estimations already exist for the critical velocity based on the wave overtopping simulations. This makes it possible to compare these values with the critical velocity resulting from the sod pulling tests. In Figure 7 all the results from the sod pulling tests have been plotted. Because of the scatter in the results it is beneficial to use the average and standard deviations from Table 1 . The values for $\sigma_{\text {grass,c }}$ are based on all the regular tests carried out at the same location calculated with the practical method for the strength of an intact grass sod.

During wave overtopping conditions damage will start to occur at the weakest part of the slope. Therefore the critical grass normal stress in the critical velocity formula should have an estimate for the weakest part of the grass sod. This estimation can be based on a distribution type for the heterogeneity of grass. Normal distributions are important in statistics and are often used in the natural sciences for real-valued random variables for which the distributions are not known. The normal distribution is useful because of the central limit theorem, which states that under mild conditions the mean of many random variables independently drawn from the same distribution, is distributed normally, irrespective of the form of the original distribution.

In order to find the governing strength of the grass sod, it is assumed that a certain percentage in the normal distribution can represent the weakest parts of the sod. In Figure 9 all the critical grass normal stresses are plotted against their relative occurrence per location. Also the normal distribution is shown with certain limits as a function of the standard deviation $\sigma$. All the individual locations resemble a normal distribution quite well and the same is true for all the locations combined. Only one test result from Millingen is outside of the expected range of the normal distribution. Therefore, this test is neglected in further analyses.

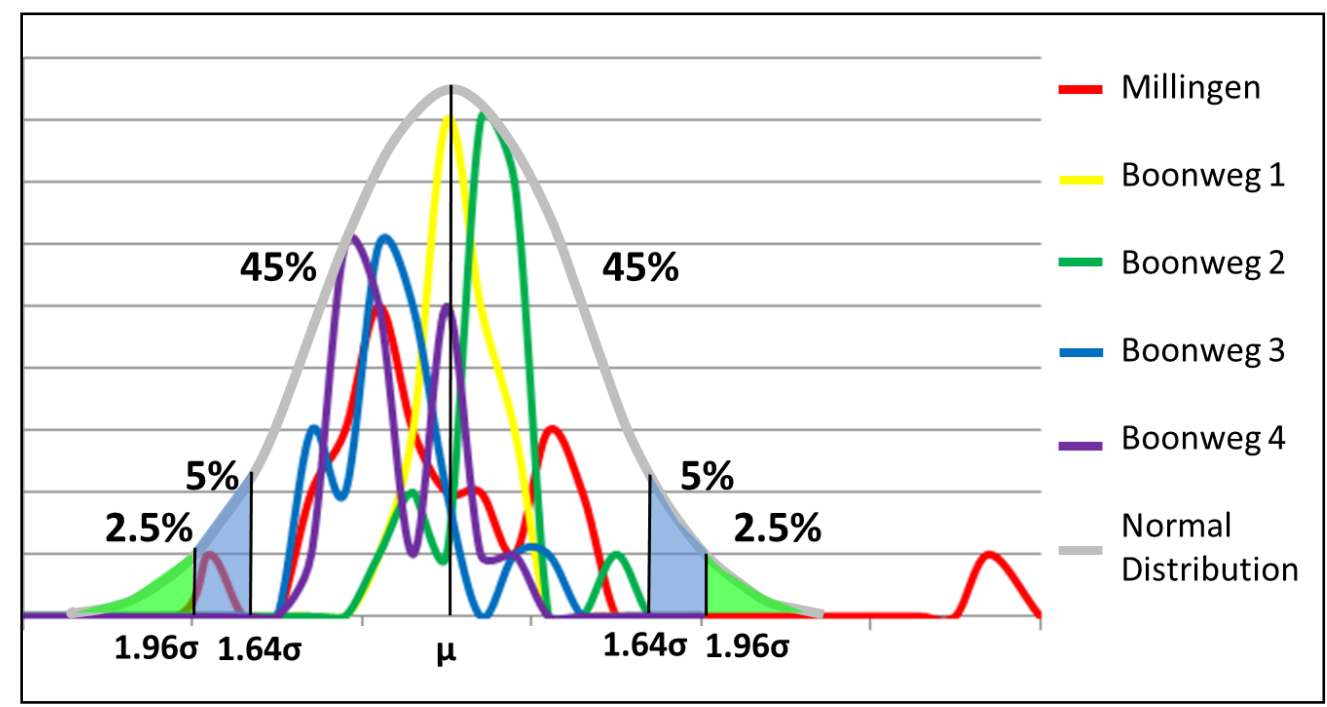

Figure 9. Normal distribution with its limits as function of the standard deviation 
The interesting points in the normal distribution are in the tails of the distribution, where the $95 \%$ limit can be found $1.96 \sigma$ away from the average value. This limit is for both tails, on either side of the average. For a grass sod only the weakest parts are important for damage during wave overtopping. This results in $2.5 \%$ limit of the normal distribution. This tail size is also chosen because when the photos of the wave overtopping tests are further analyzed, multiple spots which are most susceptible to erosion of the grass sod can be identified. These spots cover approximately $2 \%$ of the total tested area, corresponding to the $2.5 \%$ limit for a normal distribution. This results in the strength values for the weakest parts of the sod, see Table 3 .

\begin{tabular}{|c|c|c|c|}
\hline Location & $\mu$ & $\sigma$ & $2,5 \%$ limit \\
\hline Millingen & 1.18 & 0.27 & 0.65 \\
\hline Boonweg 1 & 1.28 & 0.10 & 1.08 \\
\hline Boonweg 2 & 1.37 & 0.14 & 1.10 \\
\hline Boonweg 3 & 1.10 & 0.17 & 0.77 \\
\hline Boonweg 4 & 1.10 & 0.14 & 0.83 \\
\hline
\end{tabular}

\section{Critical velocity of the tested sections}

All the parameters have now been determined for the relation between the sod pulling tests and the critical velocity formula. It is important to compare the outcome of this calculation with the results from the wave overtopping simulations. If they lead to the same results, the sod pulling test can be used for the determining of the strength of the grass sod during wave overtopping. In Table 4 the five tested locations are shown, with the corresponding critical grass normal stresses (in $\mathrm{N} / \mathrm{cm}^{2}$ ). The right side of the table shows the critical velocities (in $\mathrm{m} / \mathrm{s}$ ), where the "Calculated" values are based on the sod pulling tests in combination with Equation 5 and the "Determined" values are based on the wave overtopping simulator tests. In the calculated values from the sod pulling tests, the relative turbulence intensity is taken constant at 0.12 . In the determined values, the critical velocity of the Boonweg 1 and 2 is estimated with the damage criterion for "no sign of damage".

\begin{tabular}{|c|c|c|c|}
\hline & \multicolumn{3}{|c|}{ Critical velocity Uc [m/s] } \\
\hline Location & Calculated & Determined & Difference \\
\hline Millingen & 7.23 & 7 & $3 \%$ \\
\hline Boonweg 1 & 9.33 & $8-9.5$ & $2-16 \%$ \\
\hline Boonweg 2 & 9.38 & $8-9.5$ & $1-17 \%$ \\
\hline Boonweg 3 & 7.85 & 8 & $-2 \%$ \\
\hline Boonweg 4 & 8.14 & 8 & $2 \%$ \\
\hline
\end{tabular}

It can be seen from the table that there is a strong correlation between both values of the critical velocity for Millingen and the Boonweg 3 and 4. This is especially the case when the calculated results are rounded off. This is also done for the critical velocities from the wave overtopping simulations.

For Boonweg 1 and 2 it is a bit harder to determine the correlation, since there is a range of estimations for the critical velocity from the wave overtopping simulator tests. The calculated values for the critical velocity from the sod pulling tests are well inside this range. When the damage criterion 'No sign of damage' is closer to $1000 \mathrm{~m}^{2} / \mathrm{s}^{2}$ than $7000 \mathrm{~m}^{2} / \mathrm{s}^{2}$, the determined critical velocities based on the overtopping simulations approaches $9.5 \mathrm{~m} / \mathrm{s}$. The calculated critical velocities from the sod pulling tests are also close to this $9.5 \mathrm{~m} / \mathrm{s}$. This could lead to the assumption that Boonweg 1 and 2 are stronger than previously expected based on the wave overtopping simulations, where they thought that these sections had approximately the same strength as Boonweg 3 and 4 . If on the other hand the critical velocity of the Boonweg 1 and 2 is indeed closer to $8 \mathrm{~m} / \mathrm{s}$ than $9.5 \mathrm{~m} / \mathrm{s}$, the sod pulling tests can still be used to give an approximation of the strength of different dike sections.

\section{CONCLUSIONS AND RECOMMENDATIONS}

The sod pulling test can be used as a predictor for the strength of the grass sod. It provides results that are reliable enough to determine the critical velocity of a dike section. The distribution of forces measured during the tests need to be rewritten into a critical grass normal stress which is one of the input parameters for the assessment of the critical velocity of the grass sod. 
It is important for further studies of the behavior of the grass sod to combine the wave overtopping simulations and the sod pulling tests. For validation of formulae it is good to perform sod pulling tests on a dike section before it will be tested with the wave overtopping simulator in the future. The results from the sod pulling test can be used to give an estimation of the critical velocity of the slope. Afterwards, wave overtopping simulations can start so that the critical velocity can also be determined based on these simulations. The results from both methods should than be compared in order to validate the given relationship. It is advised to do at least 40 sod pulling tests at random locations on the bottom half of the slope in order to establish the parameters for the normal distribution and find the $2.5 \%$ tail value. These tests should be performed as condition 2 with the 20 by 20 centimeters frame size and under fully saturated conditions.

Further study could also be done into the behavior of the relative turbulence intensity along the slope, since this is an uncertain factor and it should be a load factor instead of a strength parameter. Additional research into the relation between the sod pulling tests and the loads during wave run-up and wave breaking could also be interesting.

\section{REFERENCES}

Alterra, 2014. Seizoensverloop in de doorworteling van dijkgrasland. Harde kustverdediging KB-01-011-005. [in Dutch only]

Dean, R.G., J.D. Rosati, T.L. Walton and B.L. Edge, 2010. Erosional equivalences of levees: Steady and intermittent wave overtopping, Journal of Ocean Engineering 37 (2010) 104-113.

Deltares, 2013, Evaluation and Model Development - Grass Erosion Test at the Rhine dike, 1207811002, 1207811-002-HYE-0007-svb, December 2013

EurOtop, 2016. Manual on wave overtopping of sea defences and related structures. An overtopping manual largely based on European research, but for worldwide application. Authors: Van der Meer, J.W., Allsop, N.W.H., Bruce, T., De Rouck, J., Kortenhaus, A., Pullen, T., Schüttrumpf, H., Troch, $P$. and Zanuttigh, $B$.

Hoffmans, G., G.J. Akkerman, H. Verheij, A. Van Hoven and J.W. Van der Meer, 2008. The erodibility of a grassed inner dike slopes against wave overtopping, ASCE, Proc. ICCE 2008, Hamburg. pp. 3224-3236

Hoffmans, G.J.C.M., 2012. The influence of turbulence on soil erosion, Eburon, Delft.

Infram, 2008, Factual Report: Golfoverslagproeven Friese Waddenzeedijk, Report 07i107B, 08-09-2008. [in Dutch only]

Rijkswaterstaat, 2012, Handreiking toetsen grasbekledingen op dijken t.b.v. het opstellen van het beheerdersoordeel (BO) in de verlengde derde toetsronde, Report 07i107B, 25-10-2012. Authors: Jentsje van der Meer, André Van Hoven, Maurice Paulissen, Gosse Jan Steendam, Henk Verheij, Gijs Hoffmans and Gerard Kruse. [in Dutch only]

SBW, 2012. SBW Wave overtopping and grass cover strength - Model development, Deltares report 120616-007, June 2012. Authors: Gosse Jan Steendam, Gijs Hoffmans, Jan Bakker, Jentsje Van der Meer, Joep Frissel, Maurice Paulissen and Henk Verheij

Steendam, G.J., Y. Provoost and J.W. Van der Meer, 2012. Destructive wave overtopping and wave run-up tests on grass covered slopes of real dikes, ASCE, Proc. ICCE 2012, Santander, Spain

Steendam, G.J., A. Van Hoven, J.W. Van der Meer and G. Hoffmans, 2014. Wave overtopping simulator test on transitions and obstacles at grass covered slopes of dikes, ASCE, proc. ICCE 2014, Seoul, South Korea

Steendam, G.J., A. Van Hoven and J.W. Van der Meer, 2016. Wave run-up simulation on real dikes. ASCE, proc. ICCE 2016, Antalya

Van der Meer, J.W., G.J. Steendam, G. de Raat and P. Bernardini, 2008. Further developments on the wave overtopping simulator. ASCE, proc. ICCE 2008, Hamburg

Van der Meer, J.W., B. Hardeman, G.J. Steendam, H. Schüttrumpf and H. Verheij, 2010. Flow depths and velocities at crest and inner slope of a dike, in theory and with the wave overtopping simulator, ASCE, Proc. ICCE 2010, Shanghai

Van der Meer, J.W., G.J. Steendam and A. van Hoven, 2015. Validation of cumulative overload method based on tests by the new wave run-up simulator. ASCE, Proc. Coastal Structures, Boston. 